\title{
Interaction between Poly(L-ornithine) and Sulfated Poly(vinyl alcohol)
}

\author{
Chong Su CHO, Tadashi Kōmoto,* and Tohru KAWAI \\ Department of Polymer Technology, Tokyo Institute of Technology, \\ Ookayama, Meguro-ku, Tokyo 152, Japan.
}

(Received February 13, 1979)

\begin{abstract}
Studies were made on the conformational changes of poly(L-ornithine) (PLO) by interaction with sulfated poly(vinyl alcohol)s (PVS) as functions of $\mathrm{pH}$, temperature, the degree of sulfation and the composition of the polymeric moieties. Polymer-polymer interaction took place below $c a$. pH 10.6, while no interaction of PLO with PVS was found at $c a$. $\mathrm{pH} 12.0$. PLO took on a random coil conformation through complex formations with PVS-25 and PVS-30 (the number indicates the degree of sulfation in $\mathrm{mol} \%$ ) at low $\mathrm{pHs}$. In these complexes with PVS-46 and PVS-95, the $\alpha$-helix and the $\beta_{2}$-form of PLO were formed at $1.5^{\circ} \mathrm{C}$ in the acidic $\mathrm{pH}$ region and in the $\mathrm{pH}$ region from $c a .8 .8$ to $c a$. 10.5 , respectively. The conformation of PLO in the complexes is also discussed in terms of the free-energy change resulting from the conformational change from random coil to the $\alpha$ helix.
\end{abstract}

KEY WORDS Polymer Complex / Poly(L-ornithine)/ Sulfated Poly(vinyl alcohol) / Circular Dichroism / Conformational Change /

In a previous paper, ${ }^{1}$ we studied the interaction between poly(L-lysine) (PLL) and partially sulfated poly(vinyl alcohol)s: PVS-25, PVS-30, PVS-46 and PVS-95 (The number indicates the degree of sulfation in $\mathrm{mol}^{\mathrm{o}}$.) as a model for the polypeptide-polysaccharide complex in biological connective tissue. It was found that PLL takes on a random coil conformation in the PLL-PVS-25 complex, a random coil conformation including a small amount of $\alpha$-helix in the PLL-PVS-30 complex, and the $\alpha$-helix in the PLL-PVS-46 and PLL-PVS-95 complexes over a wide range of $\mathrm{pH}$, from 2 to 12 .

Furthermore, a study was also made on the PLL-PVS-acridine orange complexes to elucidate the structure of the PLL-PVS complexes. ${ }^{2}$ The PLL-PVS-25-acridine orange complex did not give the acridine orange-induced circular dichroism (CD), indicating a random arrangement of the acridine orange molecules bound to the VS groups in the PLL-PVS-25 complex. The PLL-PVS30-acridine orange complex gave a small acridine

* To whom all the correspondences should be addressed. orange-induced Cotton effect. The PLL-PVS46-acridine orange and PLL-PVS-95-acridine orange complexes gave well-defined induced $C D$ spectra with small troughs at $435 \mathrm{~nm}$ and $510 \mathrm{~nm}$ and a large peak at $465 \mathrm{~nm}$, indicating a righthanded superhelix of the acridine orange molecules around the right-handed $\alpha$-helix of PLL chain, where the PVS chain is intercalated. It is probable, however, that the PVS chain segments are arranged in both right- and left-handed superhelices around the PLL helix.

Gelman et al. ${ }^{3}$ studied the interactions between various cationic polypeptides and polysaccharides as functions of side chain lengths of the polypeptides and structures of the polysaccharides.

Since the PVS chain is more flexible than polysaccharide, differences may be found in the interactions of PVS and polysaccharides with polypeptide (i.e., in this case PLO).

In this paper, we discuss the interaction between poly(L-ornithine) (PLO) and PVS, the former having a similar but shorter (by one $\mathrm{CH}_{2}$ ) side chain group than that of PLL and taking a conformation with an $\alpha$-helix content less than that for PLL in aqueous solution at high $\mathrm{pH}^{4,5}$ It is of interest to 
examine the conformation of PLO in the PLO-PVS complexes formed as functions of the degree of sulfation, temperature, $\mathrm{pH}$, and the conformation of PLO (without any other polymer) in aqueous solution.

\section{EXPERIMENTAL}

\section{Materials}

A high-molecular-weight PLO $\left([\eta]_{\mathrm{DMF}}^{25^{\circ}}=1.65\right.$ $\mathrm{dl}^{-1}$ ) was used as PLO hydrobromide obtained from $\operatorname{poly}(\delta$ - $N$-carbobenzoxy-L-ornithine) which had been synthesized from the corresponding amino acid $\mathrm{N}$-carboxyanhydride in dioxane at $25^{\circ} \mathrm{C}$ using triethylamine as initiator. The PVS samples are the same as used in our previous work. ${ }^{1,2}$

\section{Preparation of PLO-PVA Mixtures in Aqueous Solution}

Aqueous solutions of $6.6 \times 10^{-4}$ unit $\mathrm{moll}^{-1}$ of PLO and $6.6 \times 10^{-4}$ VS-unit $\mathrm{moll}^{-1}$ of PVS, adjusted by $\mathrm{HCl}$ and $\mathrm{NaOH}$ to the same $\mathrm{pH}$, were mixed by dropwise addition of the PVS solution to the PLO solution with stirring. The concentrations of PLO and PVS were $3.3 \times 10^{-4}$ unit $\mathrm{moll}^{-1}$, respectively after mixing.

\section{Circular Dichroism (CD) Measurement}

CD spectra of PLL-PVS mixed solutions were recorded in a thermostated quartz cell with a path length of $1.0 \mathrm{~mm}$, using a JASCO J-20 Recording Spectropolarimeter.

\section{RESULTS AND DISCUSSION}

pH Dependence of the Conformation of PLO in the

$P L O-P V S$ Mixtures at $1.5^{\circ} \mathrm{C}$

PLO, whose $\alpha$-helix is less stable than PLL, ${ }^{4,6}$ undergoes a coil-to- $\alpha$-helix transition by cooling at a high $\mathrm{pH}$ such as $c a$. 11.5. Figure 1 shows the $\mathrm{CD}$ spectra of $\mathrm{PLO}$ at $\mathrm{pH} 12.0$ at $25^{\circ} \mathrm{C}$ and $1.5^{\circ} \mathrm{C}$, indicating an increase in helical content with decrease in temperature, although the helicity was not so high at $1.5^{\circ} \mathrm{C}$ as compared with the reported values of $c a .100 \%{ }^{6}$ and $80 \%{ }^{\circ}$ It is of interest, therefore, to examine the conformation of PLO in the PLO-PVS mixtures at various temperatures as compared with that of PLL in the PLL-PVS complexes already reported. ${ }^{1}$ Figures $2-5$ show the CD spectra of PLO-PVS-25, PLO-PVS-30,

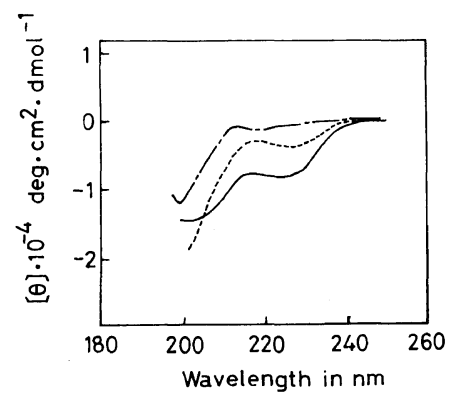

Figure 1. $\mathrm{CD}$ spectra of poly(L-ornithine) at $\mathrm{pH} 12.0$ and $1.5^{\circ} \mathrm{C}(-)$, at $\mathrm{pH} 12.0$ and $25^{\circ} \mathrm{C}(-----)$, and at $\mathrm{pH}$ 8.7 and $25^{\circ} \mathrm{C}(---)$.

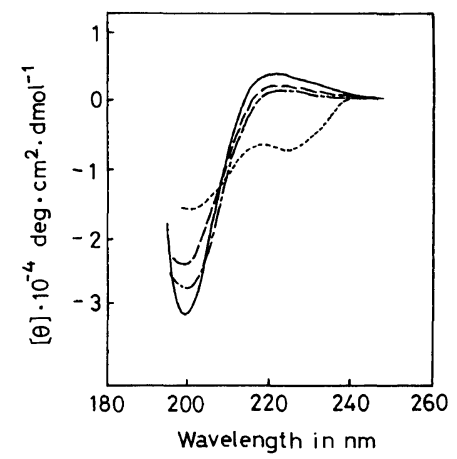

Figure 2. CD spectra of poly(L-ornithine) (PLO)-25 $\mathrm{mol} \%$ sulfated poly(vinyl alcohol) (PVS-25) mixtures at $1.5^{\circ} \mathrm{C}$ as a function of $\mathrm{pH}$. Residue concentration, $[\mathrm{LO}]=[\mathrm{VS}]=3.3 \times 10^{-4} \mathrm{moll}^{-1} \cdot \mathrm{pH} 5.1(-)$, pH 9.0 (-- $)$, pH 10.4 (----), and pH 12.0 (----).

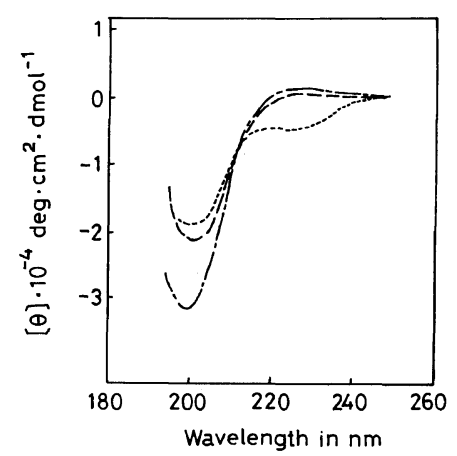

Figure 3. $\mathrm{CD}$ spectra of poly(L-ornithine) (PLO)-30 $\mathrm{mol} \%$ sulfated poly(vinyl alcohol) (PVS-30) mixtures at $1.5^{\circ} \mathrm{C}$ as a function of $\mathrm{pH}$. Residue concentration, $[\mathrm{LO}]=[\mathrm{VS}]=3.3 \times 10^{-4} \mathrm{moll}^{-1} \cdot \mathrm{pH} 9.3(---), \mathrm{pH} 10.6$ (----), and pH 12.0 (-----). 


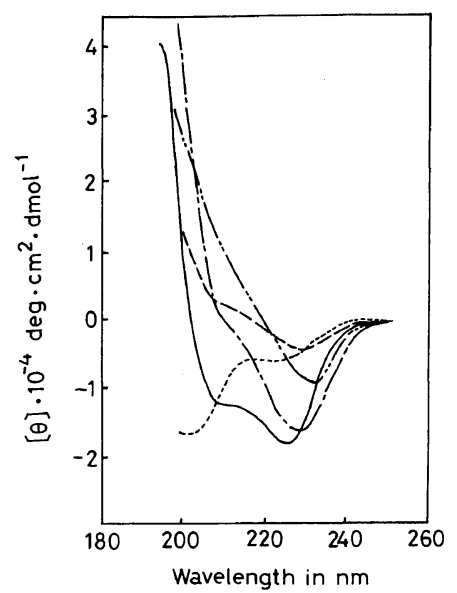

Figure 4. $\mathrm{CD}$ spectra of poly(L-ornithine) (PLO)-46 $\mathrm{mol} \%$ sulfated poly(vinyl alcohol) (PVS-46) mixtures at $1.5^{\circ} \mathrm{C}$ as a function of $\mathrm{pH}$. Residue concentration, $[\mathrm{LO}]=[\mathrm{VS}]=3.3 \times 10^{-4} \mathrm{moll}^{-1} \cdot \mathrm{pH} 5.8(-), \mathrm{pH} 9.1$ (-- $)$, pH 9.8 (-- - ) pH 10.5 (---), and pH 12.0 (-----).

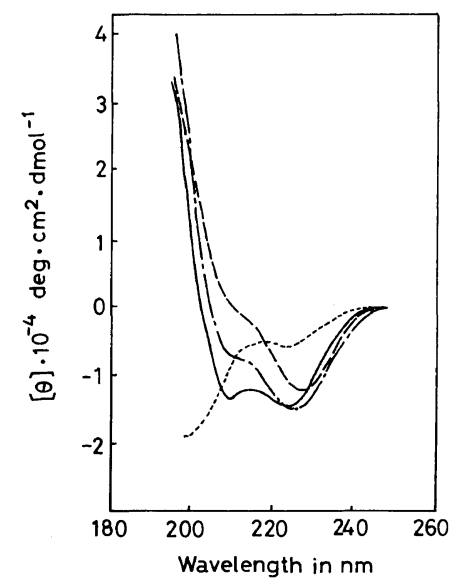

Figure 5. CD spectra of poly(L-ornithine) (PLO)-95 $\mathrm{mol} \%$ sulfated poly(vinyl alcohol) (PVS-95) mixtures at $1.5^{\circ} \mathrm{C}$ as a function of $\mathrm{pH}$. Residue concentration, $[\mathrm{LO}]=[\mathrm{VS}]=3.3 \times 10^{-4} \mathrm{moll}^{-1} \cdot \mathrm{pH} 5.8(-), \mathrm{pH} 8.8$ (-- $)$, pH 10.5 (----), and pH 12.0 (-----).

PLO-PVS-46, and PLO-PVS-95, respectively as a function of $\mathrm{pH}$ at $1.5^{\circ} \mathrm{C}$, the temperature at which the mixture solutions were prepared.

In the PLO-PVS-25 (Figure 2), PLO took on an almost random coil conformation at $\mathrm{pH}$ 5.1. The $[\theta]$ at $c a .198 \mathrm{~nm}$, which is characteristic of a random coil, increased with increasing $\mathrm{pH}$ and the $\mathrm{CD}$ spectrum at $\mathrm{pH} 12.0$, which is similar to the corresponding spectrum of PLO (Figure 1), indicates a partial $\alpha$-helix conformation. A similar $\mathrm{pH}$ dependency of $C D$ spectrum was also obtained for the PLO-PVS-30 (Figure 3). It may be said from these results that PLO takes on a random coil conformation at $1.5^{\circ} \mathrm{C}$ below ca. $\mathrm{pH} 10.6$ in the PLO-PVS-25 and the PLO-PVS-30 mixtures, and this is in good agreement with PLL-PVS-25 at room temperature.

A great difference in the conformation between PLL and PLO in the mixtures with PVS-25 and PVS-30 was found at high pHs above 11.5. Namely, PLL took on only a random coil formation even at high pHs in the PLL-PVS-25, indicating a strong interaction between PLL and PVS-25, breaking the $\alpha$-helix of PLL to form the random coil. On the other hand, the formation of the partial $\alpha$-helix conformation in the PLO-PVS-25 and the PLO-PVS-30 mixtures suggests that there is almost no interaction between the ionic moieties at $\mathrm{pH} 12.0$ and $1.5^{\circ} \mathrm{C}$. However, the difference in the value of [ $\theta]$ at $c a .199 \mathrm{~nm}$ between PLO (Figure 1) and PLO-PVS-25 and -30 (Figures 2 and 3) in the neutral and acidic $\mathrm{pH}$ regions may suggest that there is an interaction between PLO and PVS-25 and -30. This is plausible since PLO is protonated $\left(\mathrm{p} K_{\mathrm{a}}=9.8^{6}\right)$ and PVS-25 and PVS-30 are dissociated as strong polyelectrolytes even at neutral and acidic $\mathrm{pHs}$.

The CD spectra of the PLO-PVS-46 and the PLO-PVS-95 mixtures (Figures 4 and 5, respectively) indicate rather complicated conformational changes occurring with $\mathrm{pH}$. It is of interest that, at $\mathrm{pH} 5.8$ the $\alpha$-helix of PLO occurred in the mixtures and this helicity was much higher than that for PLO only at $\mathrm{pH} 12.0$ and $1.5^{\circ} \mathrm{C}$. The $\alpha$-helix formation in the PLO-PVS-46 and PLO-PVS-95 complexes at $\mathrm{pH}$ 5.8 and $1.5^{\circ} \mathrm{C}$ is quite similar to those in the PLL-PVS-46 and the PLL-PVS-95. ${ }^{1}$ The magnitude of the negative ellipticity, $[\theta]$ at $c a .209 \mathrm{~nm}$ decreased more than that at $c a .222-225 \mathrm{~nm}$ with increasing $\mathrm{pH}$, the latter $\mathrm{CD}$ trough having been red-shifted up to $c a$. $230 \mathrm{~nm}$. This change in the Cotton effect with $\mathrm{pH}$ should correspond to the conformational change from the $\alpha$-helix to the socalled $\beta_{2}$-form, ${ }^{8-16}$ since the wavelength of $c a$. $230 \mathrm{~nm}$ of the CD trough for the PLO-PVS-46 and the PLO-PVS-95 is close to $c a$. $225 \mathrm{~nm}$ for the $\beta_{2}$ - 
form. It is noteworthy that the $\beta$-structure of PLO has not been reported so far and that the $\beta_{2}$-form is preferable for PLO since PLL does not take the $\beta_{2}$ form but the $\beta_{1}$-form, which has a CD trough at $c a$. $217 \mathrm{~nm} .{ }^{17}$ In fact, PLL does not take the $\beta_{2}$-form but the $\beta_{1}$-form as a minor fraction, the major fraction being the $\alpha$-helix, in the PLL-PVS complexes. ${ }^{1}$

The $\beta_{2}$-structure of PLO is predominantly formed in $\mathrm{pH}$ region around the $\mathrm{p} K_{\mathrm{a}}$ of PLO (9.8) in the PLO-PVS-46 and the PLO-PVS-95, being accompanied by formation of a small amount of precipitate which suggests the formation of the intermolecular $\beta$-structure. The above result reveals the $\alpha$-helix-to-the $\beta_{2}$-form (abbreviation, $\alpha-\beta_{2}$ ) transition of PLO in the PLO-PVS-46 and PLO-PVS-95 complexes around the neutral $\mathrm{pH}$ region at a low temperature such as $1.5^{\circ} \mathrm{C}$.

It is also of interest that for the PLO-PVS-46 and PLO-PVS-95, the $[\theta]$ value at $c a$. $230 \mathrm{~nm}$ decreased with increasing $\mathrm{pH}$ from $c a .9$ to 10.5 and that the partial $\alpha$-helix conformation, with helical content considerably lower than that at $\mathrm{pH} 5.8$, could be observed at pH 12.0. This clearly indicates the $\beta_{2}$-to$\alpha$ transition in a high $\mathrm{pH}$ region such as $c a$. $\mathrm{pH} 10$ 11. At $\mathrm{pH} 10.5$, the $\beta_{2}$-structure was more stable in the PLO-PVS-95 than in the PLO-PVS-46, the latter seeming to have mixed conformations of comparable amounts of the $\alpha$-helix, the $\beta_{2}$-form and the random coil. This is probably due to the difference in the charge density between PVS-46 and PVS-95, giving rise to the difference in the strength of the interaction between PLO and PVS. Thus, the $\beta_{2}$-to- $\alpha$ transition may take place at $c a$. $\mathrm{pH} 10.5$ and $\mathrm{pH} 11.0-11.5$ for the PLO-PVS-46 and the PLO-PVS-95, respectively.

Comparison of the low $\alpha$-helix content at $\mathrm{pH} 12.0$ with the high content value at $\mathrm{pH} 5.8$ for the PLO-PVS-46 and the PLO-PVS-95 mixtures may indicate that there is no interaction of PLO with PVS-46 and PVS-95 at pH 12.0, since the content value is independent of the charge density of PVS as in the cases of PLO-PVS-25 and PLO-PVS-30, even though PLO without any other polymers takes on a random coil formation at the neutral and acidic $\mathrm{pHs}$ and the $\alpha$-helix at high pHs.
Effect of Temperature on the Conformation of PLO in the PLO-PVS Mixture

Taking into consideration the conformation of PLO sensitive to $\mathrm{pH}$ and temperature via the charge density of the counter polyion, PVS, examination is made of the conformational stability of PLO in the PLO-PVS mixtures when the temperature is raised from $1.5^{\circ} \mathrm{C}$ to $25^{\circ} \mathrm{C}$. Figures $6-9$ show the $\mathrm{CD}$ spectra of PLO-PVS-25, PLO-PVS-30, PLO-PVS46 and PLO-PVS-95, respectively after the mixtures, prepared at $1.5^{\circ} \mathrm{C}$, were kept at $1.5^{\circ} \mathrm{C}$ for $1 \mathrm{~h}$ and then at $25^{\circ} \mathrm{C}$ for $30 \mathrm{~min}$.

As for the PLO-PVS-25, the CD spectra shown in Figures 2 and 6 at the same $\mathrm{pH}$ are quite similar to each other except those at $\mathrm{pH}$ 12.0. Obviously, this indicates that the strong interaction, i.e., the complex formation of PLO with PVS-25 was maintained when the temperature was increased in the neutral and acidic $\mathrm{pH}$ regions. The decrease in the helicity with increasing temperature at $\mathrm{pH} 12.0$, which is quite similar to the $\alpha$-to-random coil transition by raising the temperature for PLO without PVS-25 (Figure 1), reveals no interaction between PLO and PVS-25, as anticipated from Figure 2. The quite similar phenomena should take place in the PLO-PVS-30 mixture, as evident from

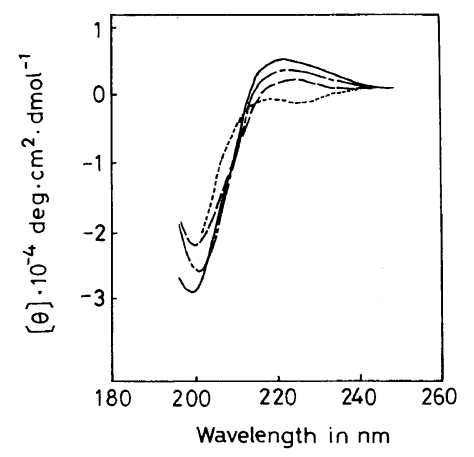

Figure 6. $\mathrm{CD}$ spectra of poly(L-ornithine) (PLO)-25 $\mathrm{mol} \%$ sulfated poly(vinyl alcohol) (PVS-25) mixtures at $25^{\circ} \mathrm{C}$ as a function of $\mathrm{pH}$. The mixture solution was prepared and kept for $1 \mathrm{~h}$ at $1.5^{\circ} \mathrm{C}$ and then kept for $30 \mathrm{~min}$ at $25^{\circ} \mathrm{C}$. pH 5.1 (—), $\mathrm{pH} 9.0(--\longrightarrow), \mathrm{pH} 10.4$ (----), and pH 12.0 (-----). 
Poly(L-ornithine) and Sulfated Poly(vinyl alcohol)

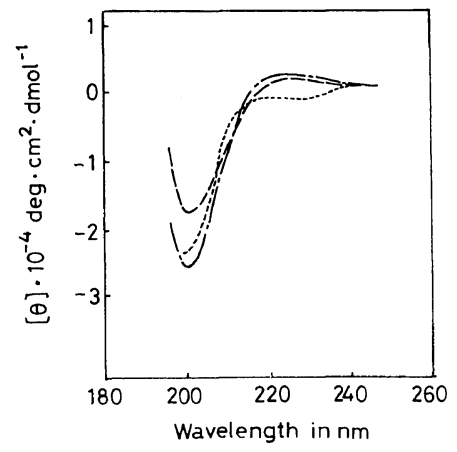

Figure 7. $\mathrm{CD}$ spectra of poly(L-ornithine) (PLO)-30 $\mathrm{mol} \%$ sulfated poly(vinyl alcohol) (PVS-30) mixtures at $25^{\circ} \mathrm{C}$ as a function of $\mathrm{pH}$. The mixture solution was prepared and kept for $1 \mathrm{~h}$ at $1.5^{\circ} \mathrm{C}$ and then kept for $30 \mathrm{~min}$ at $25^{\circ} \mathrm{C}$. pH $9.3(---), \mathrm{pH} 10.6(---)$, and $\mathrm{pH}$ $12.0(----)$.

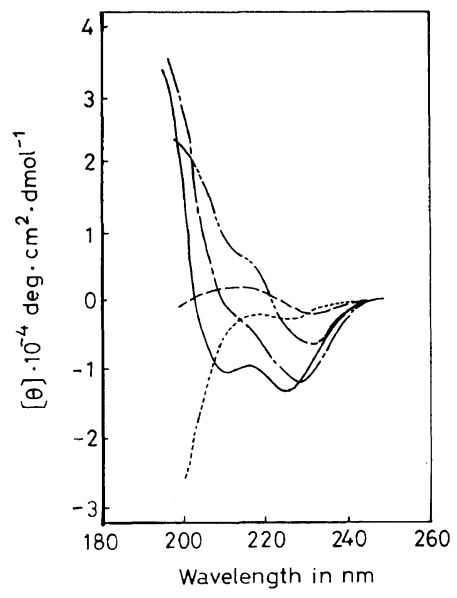

Figure 8. CD spectra of poly(L-ornithine) (PLO)-46 $\mathrm{mol} \%$ sulfated poly(vinyl alcohol) (PVS-46) mixtures at $25^{\circ} \mathrm{C}$ as a function of $\mathrm{pH}$. The mixture solution was prepared and kept for $1 \mathrm{~h}$ at $1.5^{\circ} \mathrm{C}$ and then kept for $30 \mathrm{~min}$ at $25^{\circ} \mathrm{C}$. pH $5.8(-)$, pH $9.1(--)$, $\mathrm{pH} 9.8$ (--- ), pH 10.5 (----), and pH 12.0 (-----).

comparison of the $\mathrm{CD}$ spectra of Figure 7 with those of Figure 3.

As for the PLO-PVS-46, it is evident from Figure 8 that, in the acidic $\mathrm{pH}$ region, the $\alpha$-helix once formed at $1.5^{\circ} \mathrm{C}$ was not broken when the temperature was raised to $25^{\circ} \mathrm{C}$. The $\alpha$-helix was also maintained at $\mathrm{pH} 5.8$ by raising the temperature for

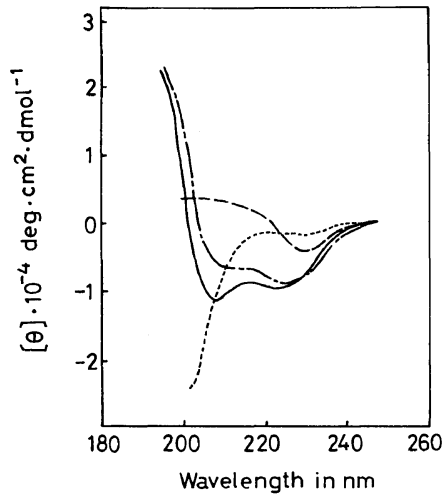

Figure 9. CD spectra of poly(L-ornithine) (PLO)-95 $\mathrm{mol}^{\circ} \%$ sulfated poly(vinyl alcohol) (PVS-95) mixtures at $25^{\circ} \mathrm{C}$ as a function of $\mathrm{pH}$. The mixture solution was prepared and kept for $1 \mathrm{~h}$ at $1.5^{\circ} \mathrm{C}$ and then kept for $30 \mathrm{~min}$ at $25^{\circ} \mathrm{C}$. $\mathrm{pH} 5.8(-), \mathrm{pH} 8.8(---), \mathrm{pH} 10.5$ (----), and pH 12.0 (-----).

the PLO-PVS-95 mixture as shown in Figure 9. Comparing the $\mathrm{CD}$ spectra of the PLO-PVS-46 mixture at $\mathrm{pH} 5.8$ at $1.5^{\circ} \mathrm{C}$ (Figure 4) and at $25^{\circ} \mathrm{C}$ (Figure 8 ), it may be said that the $\beta_{2}$-structure existing as a minor fraction decreased and that the $\alpha$-helix as the major fraction became prominent by increasing the temperature from $1.5^{\circ} \mathrm{C}$ to $25^{\circ} \mathrm{C}$. This suggests a decrease in the number of the intermolecularly associated chains.

In case of PLO-PVS-95 at pH 5.8, the magnitudes of [ $\theta]$ at $c a .198 \mathrm{~nm}$ and $c a .222 \mathrm{~nm}$ decreased with increasing temperature, indicating that a small fraction of the $\alpha$-helical PLO changed to the random coil. This may be related to the stability of the $\alpha$ helix of PLO in the acidic $\mathrm{pH}$ region. This tendency was also found at $\mathrm{pH} 8.8$ (Figures 5 and 9).

On the other hand, the $\beta_{2}$-conformation of PLO in the PLO-PVS-46 mixture was maintained by raising the temperature at $\mathrm{pH} 9.1$ and 9.8 , which are below and equal to the $\mathrm{p} K_{\mathrm{a}}$ of PLO, respectively. At $\mathrm{pH} 10.5$, change in the temperature gave rise to $\mathrm{CD}$ patterns for the PLO-PVS-46 and PLO-PVS-95 mixtures (Figures 8 and 9, respectively), from which an estimation of the conformation is very difficult. This may be partly because of a considerable amount of the precipitates.

The CD spectra of the PLO-PVS-46 (Figure 8) and the PLO-PVS-95 (Figure 9) mixtures at $\mathrm{pH} 12.0$ and $25^{\circ} \mathrm{C}$ were both similar to that of PLO without 
PVS (Figure 1). As was mentioned before, this is also evidence of almost no interaction or a very weak interaction acting between PLO and PVS at $\mathrm{pH}$ 12.0. On the other hand, it may be concluded that rather strong interactions are acting between the oppositely charged polymers below $\mathrm{pH} 9.8$, i.e., $\mathrm{p} K_{\mathrm{a}}$ of $\mathrm{PLO}$, and even at $\mathrm{pH} 10.5$.

In order to examine the conformational stability of PLO in the PLO-PVS complexes formed at acidic $\mathrm{pHs}$ at $1.5^{\circ} \mathrm{C}, \mathrm{CD}$ spectra (though not shown) were taken at various temperatures up to $80^{\circ} \mathrm{C}$ for the complexes prepared at $\mathrm{pH} 5.5$ and $1.5^{\circ} \mathrm{C}$. In the cases of the PLO-PVS-25 and the PLO-PVS-30 mixtures, the $C D$ spectra were very typical of the random coil, since the spectra are independent of temperature. PLO is also in the random coil conformation at $\mathrm{pH} 5.5$ in the absence of any other polymers. But in the case of the PLO-PVS-46 and the PLO-PVS-95 mixtures, the magnitudes of the $\mathrm{CD}$ troughs at $c a .210 \mathrm{~nm}$ and $c a .222-225 \mathrm{~nm}$ decreased with increasing temperature. As compared with the $\alpha$-to- $\beta_{1}$ transition of PLL in the PLL-PVS-46 and PLL-PVS-95 complexes with increasing temperature up to $90^{\circ} \mathrm{C},{ }^{1}$ it may be said that, PLO undergoes conformational changes from both $\alpha$ and $\beta_{2}$ to the random coil with increasing temperature in these cases.

\section{pH Dependence of the Conformation of PLO in the $P L O-P V S$ Mixtures at $25^{\circ} \mathrm{C}$}

Since the results obtained above suggest that such ordered conformations as the $\alpha$-helix and the $\beta$-form are much less stable for PLO in the complexes with PVS than in the case of PLL, examination should be made of the conformation of PLO in the PLO-PVS mixtures around room temperature. Figure 10 shows the CD spectra of the PLO-PVS-95 mixtures at various $\mathrm{pHs}$, prepared and measured at $25^{\circ} \mathrm{C}$. At $\mathrm{pH} 5.4$ and $\mathrm{pH} 7.3$, these mixtures gave $\mathrm{CD}$ spectra typical of random coils with the $\mathrm{CD}$ troughs at $c a$. $203 \mathrm{~nm}$. However, the magnitude of $[\theta]$ and the wavelength at these troughs are small and redshifted, respectively, as compared with the $\mathrm{CD}$ spectra of the PLO-PVS-25 and the PLO-PVS-30 mixtures with random coil conformations (Figures 2, 3, 6, and 7). The wavelength, $c a .203 \mathrm{~nm}$ of the CD trough for the PLO-PVS-95 mixture shown in Figure 10 is also different from $c a .198 \mathrm{~nm}$ for PLO only (Figure 1), even though the CD patterns are similar to each other. These results indicate perhaps

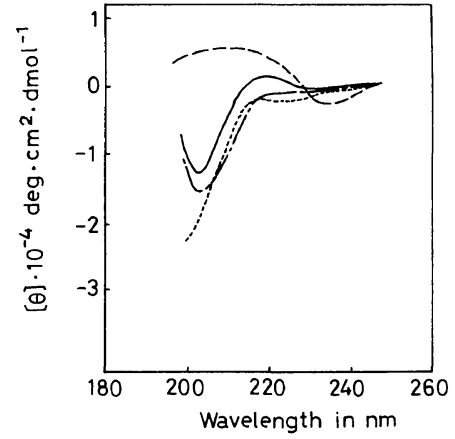

Figure 10. CD spectra of poly(L-ornithine) (PLO)-95 $\mathrm{mol}^{\%} \%$ sulfated poly(vinyl alcohol) (PVS-95) mixtures at. $25^{\circ} \mathrm{C}$ as a function of $\mathrm{pH}$. The mixture solution was prepared at $25^{\circ} \mathrm{C}$. $[\mathrm{LO}]=[\mathrm{VS}]=3.3 \times 10^{-4} \mathrm{moll}^{-1} \cdot \mathrm{pH}$ 5.4 (—), $\mathrm{pH} 7.3(--\longrightarrow), \mathrm{pH} 9.6(----)$, and $\mathrm{pH} 11.7$ $(-----)$.

that PLO forms a complex with PVS-95, and probably with the other PVS samples as well, in the acidic $\mathrm{pH}$ region at $25^{\circ} \mathrm{C}$. It is very clear, however, that, even if the PVS-95 chain is strongly associated with the PLO chain in a random coil, no transition to an ordered conformation takes place at all.

The great difference in the conformation of PLO in the PLO-PVS-95 (probably in the PLO-PVS-46 mixture as well) between at $1.5^{\circ} \mathrm{C}$ (Figure 5) and at $25^{\circ} \mathrm{C}$ (Figure 10) may be accounted for by the opposite signs of $\Delta G^{0}$, the free energy of the conformational transition from coil-to-helix: i.e., at a low temperature such as $0.8^{\circ} \mathrm{C}, \Delta G^{0}=-28 \pm 2$ cal mol ${ }^{-1}$ and at $25^{\circ} \mathrm{C}, \Delta G^{0}=$ positive for PLO only. ${ }^{6}$ The positive $\Delta G^{0}$ for $\mathrm{PLO}$ at and above $25^{\circ} \mathrm{C}$ can also account for the conformational changes from both the $\alpha$-helix and the $\beta_{2}$-form to random coil at high temperatures for the PLO-PVS-46 and the PLO-PVS-95 mixtures mentioned above. The $\alpha$ helix formation of PLL in the PLL-PVS-46 and the PLL-PVS-95 complexes at acidic $\mathrm{pHs}^{1}$ agrees well with large negative values of $\Delta G^{0}$ such as -138 cal mol${ }^{-1}$ at $25^{\circ} \mathrm{C}$ and $-168 \mathrm{cal} \mathrm{mol}^{-1}$ at $0.5^{\circ} \mathrm{C}^{6}$

\section{Effects of the Residue Mole Ratio, $[V S] /[L O]$ on the} Helicity of PLO

In order to clarify the structure of the complex of PLO with PVS, especially in the case of the $\alpha$-helix at low pHs, $[\theta]_{222}$ was measured by changing the residue mole ratio, [VS]/[LO]. Quite similarly to the 
PLL-PVS-46 and the PLL-PVS-95 complexes, ${ }^{1}$ $[\theta]_{222}$ decreased with increasing $[\mathrm{VS}] /[\mathrm{LO}]$ and became constant ( $\mathrm{ca} . \quad-1.5 \times 10^{4} \sim-1.7 \times 10^{4}$ $\operatorname{deg} \mathrm{cm}^{2} \mathrm{dmol}^{-1}$ of LO residue) for [VS]/[LO] $\geqq 1$. This is the reason why [VS]/[LO] of 1 was chosen for the $\mathrm{CD}$ measurements for examining the conformation of PLO in the PLO-PVS mixtures. Consequently, the highest helicity attained at [VS]/[LO] $\geqq 1$ (although a small amount of the $\beta_{2}$ form was contained) is very similar to the [VS]/[LL] dependency of PLL conformation for the PLL-PVS-46 and the PLL-PVS-95 complexes at low pHs, suggesting that the PVS chain is so flexible that it can undergo large conformational changes following conformations of PLL or PLO itself from the random coil to the $\alpha$-helix.

\section{REFERENCES}

1. C. S. Cho, T. Kōmoto, A. Nakagami, and T. Kawai, Makromol. Chem., 180, 1951 (1979).

2. C. S. Cho, T. Kōmoto, and T. Kawai, Makromol. Chem., 180, in press (1979).

3. R. A. Gelman and J. Blackwell, Biopolymers, 13, 139 (1974).
4. G. Blauer and Z. B. Alfassi, Biochim. Biophys. Acta, 133, 206 (1967).

5. S. R. Chaudhuri and J. T. Yang, Biochemistry, 7, 1379 (1968).

6. M. J. Grourke and J. H. Gibbs, Biopolymers, 10, 795 (1971).

7. Y. C. Fu, H. E. Van Wart, and H. A. Scheraga, Biopolymers, 15, 1795 (1976).

8. G. D. Fasman and J. Potter, Biochem. Biophys. Res. Commun., 27, 209 (1967).

9. L. Stevens, R. Townend, S. N. Timasheff, G. D. Fasman, and J. Potter, Biochemistry, 7, 3717 (1968).

10. H. Maeda and S. Ikeda, Biopolymers, 10, 1635 (1971).

11. T. Imae and S. Ikeda, Biopolymers, 11, 509 (1972).

12. C. Toniolo and G. M. Bonora, Makromol. Chem., 175, 2203 (1974).

13. C. Toniolo and G. M. Bonora, Makromol. Chem., 176, 2547 (1975).

14. C. Toniolo and G. M. Bonora, Biopolymers, 13, 2179 (1974).

15. T. Hayakawa, Y. Kondo, and Y. Murakami, Polym. J., 6, 424 (1974).

16. K. Itoh and G. D. Fasman, Biopolymers, 15, 419 (1976).

17. R. Townend, T. F. Kumosinski, S. N. Timasheff, G. D. Fasman, and B. Davidson, Biochem. Biophys. Res. Commun., 23, 163 (1966). 